\title{
Platelet-rich plasma stimulated proliferation, migration, and attachment of cultured periodontal ligament cells
}

\author{
Kanyawat Rattanasuwan ${ }^{1}$, Supanee Rassameemasmaung ${ }^{1}$, Sirichai Kiattavorncharoen ${ }^{2}$, \\ Anongporn Sirikulsathean ${ }^{1}$, Jarinee Thorsuwan ${ }^{3}$, Wilasinee Wongsankakorn ${ }^{4}$
}

Correspondence: Dr. Kanyawat Rattanasuwan Email: kanyawat3905@gmail.com

\begin{abstract}
'Department of Oral Medicine and Periodontology, Faculty of Dentistry, Mahidol University, Bangkok, Thailand, ${ }^{2}$ Department of Oral and Maxillofacial Surgery, Faculty of Dentistry, Mahidol University, Bangkok, Thailand, ${ }^{3}$ Dental Clinic, Ranong Hospital, Ranong, Thailand, 4Private Practice, Bangkok, Thailand
\end{abstract}

\section{ABSTRACT}

Objective: The aim of this study is to evaluate the effects of platelet-rich plasma (PRP) on the proliferation, migration, and attachment of cultured periodontal ligament (PDL) cells. Materials and Methods: 3-(4,5-dimethylthiazole-2-yl)-2,5-diphenyltetrazolium bromide (MTT) assay was used to assess number of PDL cells cultured in medium with or without PRP. Cell migration toward medium with or without PRP was assessed using the Boyden chamber. Cell attachment was assessed by counting cells on PRP or non-PRP coated dentin specimens. Group differences were analyzed using two-way ANOVA at 0.05 significance level. Results: In the MTT and cell migration assay, the number of cells in 5\% and 10\% PRP-treated groups were significantly higher than that in the non-PRP-treated group $(P<0.05)$. In the attachment assay, the number of cells on the dentin specimens in 10\% PRP-treated group was significantly higher than that in the non-PRP treated group $(P<0.05)$. Conclusion: PRP could stimulate proliferation, migration, and attachment of PDL cells.

Key words: periodontal ligament, platelet-rich plasma, wound healing

\section{INTRODUCTION}

Platelet-rich plasma (PRP) has been widely utilized in the periodontal regeneration. ${ }^{[1,2]}$ Theoretically, PRP can deliver several concentrated growth factors, for example, platelet-derived growth factor (PDGF) and transforming growth factor-beta (TGF- $\beta$ ) that may act simultaneously to form a cascade of different signal proteins with multiple pathway. ${ }^{[3]}$ Other than growth factors, the fibrin clot produced by fibrinogen within PRP could up-regulate type I collagen expression by periodontal ligament (PDL)

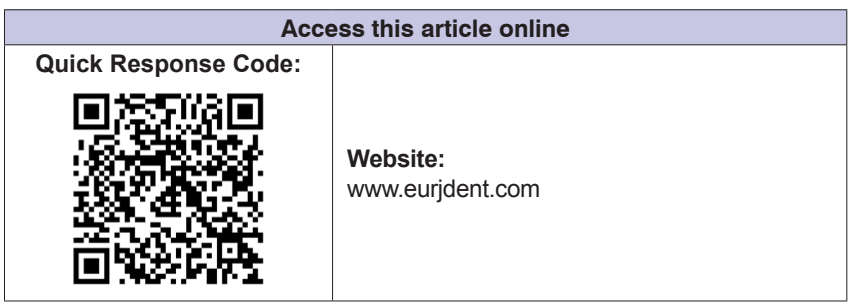

cells. ${ }^{[4]}$ PRP also increased alkaline phosphatase activity in PDL cells, while a combination of TGF- $\beta 1$ and PDGF-AB could mimic only the mitogenic actions of PRP. ${ }^{[5]}$ In addition, PRP provided platelet aggregates as nuclei to initiate mineralization by rat PDL cells. ${ }^{[6]}$ Thus, PRP should facilitate periodontal regeneration via both growth factor-dependent and factor-independent pathway.

This is an open access journal, and articles are distributed under the terms of the Creative Commons Attribution-NonCommercial-ShareAlike 4.0 License, which allows others to remix, tweak, and build upon the work non-commercially, as long as appropriate credit is given and the new creations are licensed under the identical terms.

For reprints contact: reprints@medknow.com

How to cite this article: Rattanasuwan K, Rassameemasmaung S,
Kiattavorncharoen S, Sirikulsathean A, Thorsuwan J, Wongsankakorn W.
Platelet-rich plasma stimulated proliferation, migration, and attachment
of cultured periodontal ligament cells. Eur J Dent 2018;12:469-74.
DOI: $10.4103 /$ ejd.ejd_255_17


A recent study showed that PRP could stimulate PDL fibroblast proliferation. ${ }^{[7]}$ However, the regenerative events also require migration and attachment of connective tissue cells to the wound site and synthesis of the specialized components which they are attempting to repair. Thus, the aim of this study was to evaluate the effects of PRP on the proliferation, migration, and attachment of PDL cells in vitro.

\section{MATERIALS AND METHODS}

The study protocol was documentary approved by The Committee on Human Rights Related to Human Experimentation, Mahidol University (No. 13/2005). Systemically-healthy and periodontally-healthy and nonsmoking patients who were referred for extraction of the sound teeth with orthodontic reasons at the Faculty of Dentistry, Mahidol University, were included in the study. Patients were informed about the study details and asked to sign the informed consent forms before participating.

\section{Isolation and culture of periodontal ligament fibroblasts}

PDL fibroblasts were obtained from human tissue scraped from the roots of extracted teeth. After extraction, the teeth were placed in Dulbecco's Modified Eagle's Medium (DMEM; Hyclone, Logan, UT, USA), supplemented with $0.5 \mu \mathrm{g} / \mathrm{mL}$ amphotericin $\mathrm{B}$ (Gibco, Grand Island, NY, USA), $200 \mathrm{U} / \mathrm{mL}$ penicillin G and $200 \mu \mathrm{g} / \mathrm{mL}$ streptomycin (Gibco) and washed 3 times in phosphate-buffered saline, PBS, pH 7.2. The tissue was obtained from the middle one-third of the roots, chopped into small pieces, and placed into a $25 \mathrm{~cm}^{2}$ tissue culture flask (Nunc, Roskilde, Denmark) containing DMEM supplemented with $10 \%$ fetal bovine serum (FBS; Hyclone), $0.25 \mu \mathrm{g} / \mathrm{mL}$ amphotericin $\mathrm{B}, 100 \mathrm{U} / \mathrm{mL}$ penicillin $\mathrm{G}$ and $100 \mu \mathrm{g} / \mathrm{mL}$ streptomycin. The explants were incubated at $37^{\circ} \mathrm{C}$ in humidified air containing $5 \% \mathrm{CO}_{2}$. The medium was changed every 2-3 days. After cells had grown to near confluency, they were passed and resuspended in the culture medium. Cells from passages 4 to 8 were used.

\section{Collection and preparation of platelet-rich plasma}

Autologous PRP was collected and prepared from each subject after cultured PDL cells of that particular subject reached passages $4-8$. Approximately $8.5 \mathrm{~mL}$ of whole blood was drawn from the antecubital region with a $20 \mathrm{G}$ needle and placed in a sterile tube containing an anticoagulant (acid-citric dextrose). PRP was prepared as previously described ${ }^{[8]}$ with minor modifications. Briefly, the blood was centrifuged in a general purpose cell separator (Beckman J2-21, CA, USA) at 1,300 revolutions/ $\mathrm{min}$ (rpms) for $10 \mathrm{~min}$. The blood was then separated into a lower red blood cell region and an upper straw-colored plasma region. The straw-colored plasma was drawn and again centrifuged at $2000 \mathrm{rpms}$ for $10 \mathrm{~min}$. The result of the second centrifuge consisted of an upper portion of clear yellow supernatant serum and the red-tinged bottom portion. The upper portion of serum was discarded and left approximately $1.5 \mathrm{~mL}$ of serum and concentrated platelets in the tube. PRP was stored at $-20^{\circ} \mathrm{C}$ until used.

\section{Assessment of cell proliferation}

Cell proliferation was performed by the 3-(4,5-dimethylthiazole-2-yl)-2,5-diphenyltetrazolium bromide (MTT) assay ${ }^{[9]}$ with slight modification. ${ }^{[10]}$ PDL fibroblasts were trypsinized and $2 \times 10^{4}$ cells/ well were seeded into a 96-well tissue culture plate (Nunc). The cells were maintained in $200 \mu \mathrm{L}$ of DMEM supplemented with $10 \%$ FBS and incubated at $37^{\circ} \mathrm{C}$ in humidified air containing $5 \% \mathrm{CO}_{2}$ for $24 \mathrm{~h}$. The fibroblasts were washed with PBS and incubated in $200 \mu \mathrm{L}$ of DMEM supplemented with $1 \%$ FBS (Group I), $1 \%$ FBS plus $5 \%$ (v/v) PRP (Group II) or 1\% FBS plus $10 \%$ (v/v) PRP (Group III) and incubated as previously described for $24 \mathrm{~h}$. After this, the culture medium was discarded, and $100 \mu \mathrm{L}$ of an MTT solution (prepared by dissolving $1 \mathrm{mg}$ of an MTT powder in $2 \mathrm{~mL}$ of DMEM just before use and filtered through a $0.22 \mu \mathrm{m}$ filter) were added into each well. The cells were incubated as previously described for $4 \mathrm{~h}$ before the MTT solution was discarded. The cells were washed with PBS. The formazan crystal was solubilized with $100 \mu \mathrm{L}$ of dimethylsulfoxide. The plates were shaken for $30 \mathrm{~min}$ at room temperature using a plate shaker. Plates were transferred to a spectrophotometer and absorbance was measured immediately at $540 \mathrm{~nm}$. The assay was performed in triplicate wells and repeated 3 times. In the repeated experiment, PDL fibroblasts obtained from each subject were grown individually and treated with PRP obtained from those particular subjects.

\section{Platelet-rich plasma activation}

PDL cells were seeded at a density of $5 \times 10^{4}$ cells in the culture dish and incubated for $24 \mathrm{~h}$ in DMEM containing $10 \%$ FBS. The medium was then replaced with DMEM containing 1\% FBS plus $5 \%(\mathrm{v} / \mathrm{v})$ or $10 \%(\mathrm{v} / \mathrm{v})$ PRP and left for approximately $10 \mathrm{~min}$. Then, the liquid medium formed gel, suggested that PRP was activated. Activated PRP was carefully aspirated for use in the migration and attachment assay. 


\section{Migration assay}

Migration was assessed using the Boyden chamber (Corning, NY, USA) equipped with nucleopore filters with a pore size of $8.0 \mu \mathrm{m}$ as previously described. ${ }^{[11]}$ Nucleopore filters were coated with $20 \mathrm{ng} / \mu \mathrm{L}$ fibronectin. In the bottom chamber of the well, $800 \mu \mathrm{L}$ of DMEM containing 1\% FBS (Group I), 5\% activated PRP (Group II), or $10 \%$ activated PRP (Group III) was placed. A volume of $200 \mu \mathrm{L}$ of cell suspension with a cell density of $2.5 \times 10^{5}$ cells $/ \mathrm{mL}$ in DMEM containing $1 \%$ FBS was filled in the top chamber. The assembly chemotactic chambers were incubated at $37^{\circ} \mathrm{C}$ in humidified air containing $5 \% \mathrm{CO}_{2}$ for $12 \mathrm{~h}$. After incubation, the filters were fixed for $3 \mathrm{~min}$ in absolute methanol, stained with $0.25 \%$ toluidine blue in distilled water for $2 \mathrm{~min}$, rinsed twice in distilled water and allowed to dry. Cells migrating through the filter were counted in 10 random fields under light microscope at a magnification of $\times 200$. The assay was done in triplicate and repeated 3 times.

\section{Attachment assay}

Dentin slabs were prepared as described by Wikesjö et al. ${ }^{[12]}$ Briefly, the sound and freshly extracted human teeth were cut on the vertical direction into $3 \mathrm{~mm} \times 4 \mathrm{~mm} \times 1 \mathrm{~mm} /$ piece using water-cooled diamond cutting machine (Accutom-50, Copenhagen, Denmark) and conditioned with 600 mesh sandpaper on the experimental surface to obtain a surface resembled those obtained following clinical root instrumentation. The slabs were immersed in distilled water and sterilized by autoclave.

Attachment assay was performed as described by Alleyn et al. ${ }^{[13]}$ Briefly, sterilized dentin slabs were placed into a 96-well flat bottom plate (Corning). Two $\mu \mathrm{L}$ of DMEM containing 1\% FBS (Group I), $5 \%$ activated PRP (Group II) or 10\% activated PRP (Group III) were coated on the whole top surface of the dentin slabs ( 3 dentin slabs in each group for each subject). The dentin slabs were allowed to dry for $1 \mathrm{~h}$ at $37^{\circ} \mathrm{C}$. Then, $200 \mu \mathrm{L}$ of cell suspension with a density of $5 \times 10^{4}$ cells $/ \mathrm{ml}$ were carefully added over the dentin slabs and incubated as previously described for $6 \mathrm{~h}$. After incubation, each dentin slab was rinsed twice with PBS, fixed with absolute methanol for 2 min, stained with $0.25 \%$ toluidine blue in distilled water for $2 \mathrm{~min}$ and rinsed twice with distilled water. Stained slabs were observed under a light microscope and cells attached on 10 predetermined fields were counted under a magnification $\times 40$. The data were expressed as number of cells/unit area.

\section{Statistical analysis}

Statistical analysis was performed using PASW Statistics for Windows, Version 18.0 (SPSS Inc., Chicago). The data were presented in the form of means and standard deviation. Two-way ANOVA was used for comparison between groups. The level of significance was the value of $P<0.05$.

\section{RESULTS}

Three female participants, age 21-32 years (mean 28 years) were included in the study. Mean platelet count was $218,000 / \mu \mathrm{L}$ in the whole blood and $721,000 / \mu \mathrm{L}$ in PRP. Thus, platelet recovery was $331 \%$. When PRP was mixed with DMEM supplemented with $1 \%$ FBS, the medium was gradually formed gel. However, the medium with $5 \%$ or $10 \%$ PRP was rapidly converted to gel-like material after incubation with cultured PDL cells [Figure 1a and b].

According to the proliferation and migration assay, number of cells after treated with PRP (Group II and III) were significantly higher than that without PRP (Group I), as shown in Table 1. However, no significant difference was found between Group II and III $(P>0.05)$.

At $6 \mathrm{~h}$, the attachment of PDL fibroblast cells were observed and determined under the light microscope. PDL fibroblast cells on the dentin specimens represented spindle shapes and stained positive for toluidine blue $\mathrm{O}$ in all three groups [Figure 2]. Number of attached cells in PRP-treated groups was higher than that in non-PRP-treated group. Statistical analysis revealed a significant difference in the number of attached cells between Group I and III [Table 1; $P<0.05$ ]. When the comparison was made between Group I and II as well as between Group II and III, there was no significant difference $(P>0.05)$.

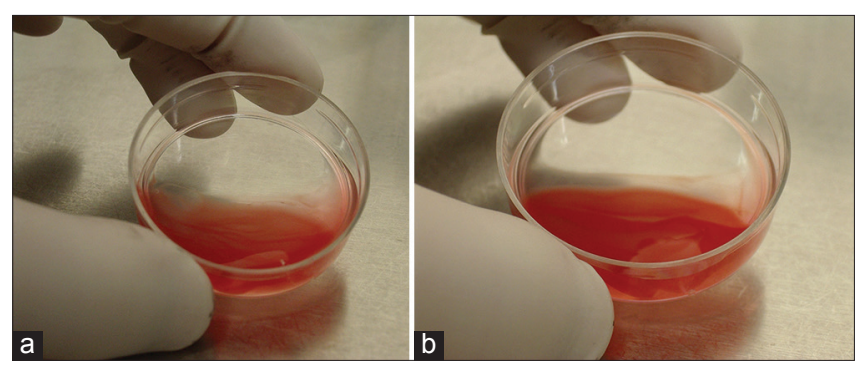

Figure 1: Conversion of medium from solution to gel-like material. (a) After periodontal ligament cells were incubated with medium containing 5\% platelet-rich plasma. (b) After periodontal ligament cells were incubated with medium containing $10 \%$ platelet-rich plasma 


\begin{tabular}{|c|c|c|c|}
\hline Assay & Group I (0\% PRP) & Group II (5\% PRP) & Group III (10\% PRP) \\
\hline Proliferation (cells) & $27,338.21 \pm 15,818.09$ & $53,359.46 \pm 29,805.75^{*}$ & $59,502.88 \pm 34,578.94 *$ \\
\hline Migration (cells) & $25.86 \pm 3.76$ & $40.87 \pm 11.36^{*}$ & $51.3 \pm 8.12^{*}$ \\
\hline Attachment (cells/unit area) & $45.08 \pm 20.76$ & $50.61 \pm 22.16$ & $53.12 \pm 23.29^{*}$ \\
\hline
\end{tabular}

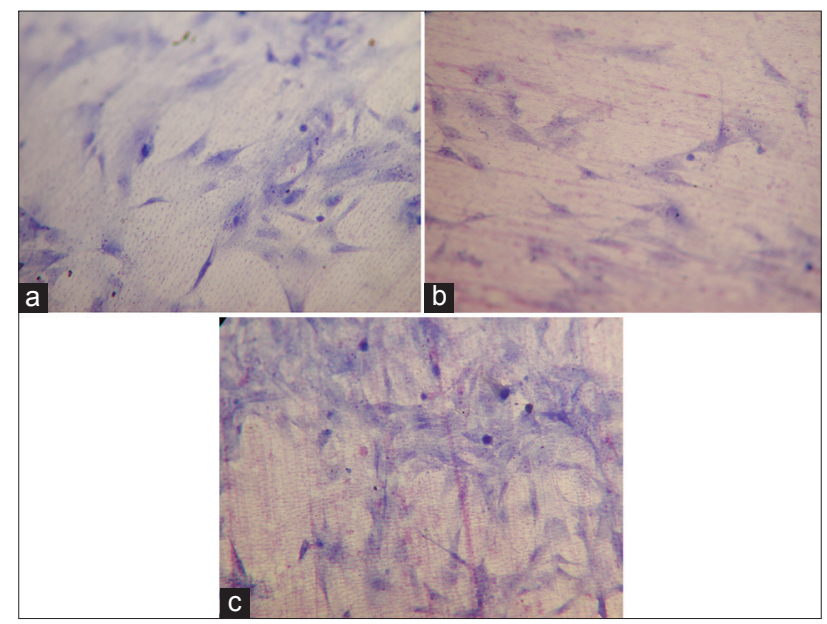

Figure 2: Toluidine blue $O$ staining of attached periodontal ligament fibroblast cells on dentin surface. (a) control group, (b) $5 \%$ platelet-rich plasma group and (c) $10 \%$ platelet-rich plasma group (magnification $\times 200$ )

\section{DISCUSSION}

Cells derived from PDL play a key role in periodontal regeneration and their early recruitment is considered critical for the regeneration to occur. ${ }^{[14]}$ PRP has been suggested to modulate PDL cell migration through a number of growth factors. ${ }^{[15]}$ However, an evidence to support this notion is lacking. In this study, we provided evidence that activated PRP could stimulate PDL cell migration. It was found that PDGF, insulin growth factor (IGF), epidermal growth factor (EGF), and TGF- $\beta$ stimulated cell migration. ${ }^{[16,17]}$ Celotti et al. ${ }^{[18]}$ also found that the migration of cultured osteoblasts was completely inhibited by the addition of anti-PDGF antibody to PRP. Thus, the migration of PDL cells may be mediated by growth factors presented in PRP.

Regarding the attachment of PDL cells, the formation of an oriented and functional apparatus could be occurred if PDL fibroblasts could attach on the root surface during wound healing. In this study, we have clearly demonstrated that the number of PDL fibroblast cells attached on dentin slabs was significantly increased in the 10\% PRP group over the $5 \%$ PRP group and the control group. In contrast, we failed to detect an advantage of $5 \%$ PRP on cell attachment. Kawase et al. ${ }^{[4]}$ separated $0.6 \mathrm{ml}$ of PRP from $8.5 \mathrm{ml}$ of the whole blood and investigated the shape of PDL fibroblast cell after treated with PRP. They found that PDL fibroblast cells had a flatten shape and pseudopodia after exposure to 5\% PRP for $24 \mathrm{~h}$. In that study, less volume of PRP was drawn and thus the PRP obtained was more concentrated. However, we found that it was hard to aspirate $10 \%$ PRP after activated since it turned to gel with high viscosity. Gamal et al. ${ }^{[19]}$ cultured PDL cells on the human recombinant growth factor-treated or nontreated dentin surface and incubated for $24 \mathrm{~h}$. They revealed a significant higher number of PDL cells on the PDGF-BB-treated and PDGF-BB plus IGF-1-treated dentin surfaces when compared to the IGF-1-treated and the nontreated dentin surfaces. The authors showed that PDGF-BB had an ability to stimulate adherence of PDL cells but this ability might probably related to its mitogenic effect on mesenchymal cells as well. It is known that many factors including fibrinogen, von Willebrand factor as well as many attachment factors such as fibronectin can be released by platelet to help control of bleeding and stabilize the wound through clot formation. Thus, other than growth factors, these components may also aid in the attachment of PDL cells. However, the dentin specimens used in this study may not mimic the condition in the oral cavity because of a variation in the root surface topography or the flow of gingival crevicular fluid that may affect the absorption of PRP onto the root dentin. This aspect has to be concerned in the clinical situation.

In this study, a significant response in proliferation was elicited in PDL cells after treated with PRP in both concentrations. The addition of 10\% PRP to the culture medium stimulated more mitogenic response in PDL cells than the addition of 5\% PRP; however, this difference was not statistically significant. From a previous study, ${ }^{[7]} 5 \%$ PRP had a greater stimulating impact on cellular proliferation but $50 \%$ PRP adversely affected cell vitality. Creeper et al. ${ }^{[20]}$ reported a cytotoxic effect of $100 \%$ PRP. Graziani et al. ${ }^{[21]}$ found that higher concentrations of PRP could reduce cell proliferation. In osteoclast proliferation, the upregulation of osteocalcin levels 
and downregulation of osteoprotegerin levels were noted with increasing PRP concentrations. Choi et al. ${ }^{[22]}$ suggested that a dilution of PRP to a level of $0.5 \%-5 \%$ would stimulate osteoblastic proliferation and might act as a mitogen on alveolar bone cells. Hence, different PRP concentrations may have different impact on the in vivo results.

PDL cell proliferation may be induced by PDGF and/or TGF-mediated mechanism since the effect of PRP on PDL cell was similar to the actions of PDGF and TGF. ${ }^{[23,24]}$ Other known growth factors contained in PRP such as basic fibroblast growth factor and EGF also stimulated PDL cell proliferation. ${ }^{[5]}$ Our result was in agreement with Okuda et al. ${ }^{[25]}$ However, Okuda et al. ${ }^{[25]}$ did not assess the effect of PRP on PDL cells obtained from the same subjects. Recently, Fréchette et al. ${ }^{[26]}$ reported a significant variations in growth factor concentrations between individuals, varying from traces (TGF- $\alpha$ ) to $5.5 \mathrm{ng} / \mathrm{mL}$ (IGF-1). Thus, in this study, we hypothesized that the effect of PRP may be subject-specific due to this variation. We assessed the effect of PRP and PDL cells which were obtained from the same subjects. Our finding that a large inter-subject variation in the number of cells was observed after exposed to PRP may provide a trend to support this hypothesis. The reasons for this variation may be explained by the variation in growth factor concentration between individual as well as the differential expression of growth factor receptors. It has been found that the $\alpha$-subunits of the PDGF receptors can bind to either PDGF-A or PDGF-B while the $\beta$-subunits can bind only to PDGF-B. Thus, PDGF-BB can bind to any one of the three receptor subunit combination $(\alpha \alpha, \alpha \beta$, and $\beta \beta)$. The finding by Seifert et al. ${ }^{[27]}$ that PDGF-BB was about 10-fold more mitogenic for human dermal fibroblasts than was PDGF-AA supported this notion.

When PRP is used, it is important to separate high concentration of platelets without fragmenting them. A concentration of $1,000,000$ platelets/ $\mu l$ has been recommended as the working definition of PRP. Since the normal range of platelets in the whole blood of healthy individuals varies from 140,000 to 400,000 platelets $/ \mu \mathrm{l}$, this means a $3-5$ fold increase over the baseline concentration..$^{[15,28]}$ In this study, we used the PRP preparation technique described by Gonshor. ${ }^{[8]}$ This technique required only a small volume of blood and could provide quiescent platelets after an entire preparation process. The PRP concentration obtained in this study was 331\% above its baseline concentration and was comparable to that obtained by the commercial office devices such as Smart PReP and PCCS. ${ }^{[29]}$ However, lower than that obtained by the study of Gonshore ${ }^{[8]}$ and may be due to the differences in the equipment used as well as the procedural effects.

The PRP concentration obtained in this study was $331 \%$ above baseline concentration but lower than that previously reported. ${ }^{[30]}$ On PRP activation, a gelatinous structure is formed and growth factors are released. The activation of PRP using bovine thrombin may be associated with the development of antibodies against contaminated bovine factor $\mathrm{V}$. The cross-reactivity of anti-bovine factor $V$ antibodies with human factor results in factor V deficiency and the risk of coagulopathies. ${ }^{[31]}$ In this study, the method used to activate PRP was followed to Kawase et al. ${ }^{[4]}$ who suggested that PRP could be activated by serine protease thrombin produced by PDL cells and this method should be developed to a clinical use.

\section{CONCLUSION}

Our pilot study revealed that PRP could modulate PDL cell proliferation, attachment, and migration in vitro and supported that the preparation technique for PRP was efficient.

\section{Acknowledgments}

The authors would like to thank the Faculty of Dentistry, Mahidol University for a grant of this study.

\section{Financial support and sponsorship}

A grant from the Faculty of Dentistry, Mahidol University.

\section{Conflicts of interest}

There are no conflicts of interest.

\section{REFERENCES}

1. Jalaluddin M, Singh DK, Jayanti I, Kulkarni P, Faizuddin M, Tarannum F, et al. Use of platelet rich plasma in the management of periodontal intra-osseous defects: A clinical study. J Int Soc Prev Community Dent 2017;7:105-15.

2. Gupta G. Clinical and radiographic evaluation of intra-bony defects in localized aggressive periodontitis patients with platelet rich plasma/ hydroxyapatite graft: A comparative controlled clinical trial. Contemp Clin Dent 2014;5:445-51.

3. Sánchez AR, Sheridan PJ, Kupp LI. Is platelet-rich plasma the perfect enhancement factor? A current review. Int J Oral Maxillofac Implants 2003;18:93-103.

4. Kawase T, Okuda K, Wolff LF, Yoshie H. Platelet-rich plasma-derived fibrin clot formation stimulates collagen synthesis in periodontal ligament and osteoblastic cells in vitro. J Periodontol 2003;74:858-64.

5. Kawase T, Okuda K, Saito Y, Yoshie H. In vitro evidence that the biological effects of platelet-rich plasma on periodontal ligament cells is not mediated solely by constituent transforming-growth factor-beta 
or platelet-derived growth factor. J Periodontol 2005;76:760-7.

6. Kawase T, Okuda K, Saito Y, Amizuka N, Suzuki H, Yoshie H, et al. Platelet-rich plasma provides nucleus for mineralization in cultures of partially differentiated periodontal ligament cells. In Vitro Cell Dev Biol Anim 2005;41:171-6.

7. Tavassoli-Hojjati S, Sattari M, Ghasemi T, Ahmadi R, Mashayekhi A. Effect of platelet-rich plasma concentrations on the proliferation of periodontal cells: An in vitro study. Eur J Dent 2016;10:469-74.

8. Gonshor A. Technique for producing platelet-rich plasma and platelet concentrate: Background and process. Int J Periodontics Restorative Dent 2002;22:547-57.

9. Mosmann T. Rapid colorimetric assay for cellular growth and survival: Application to proliferation and cytotoxicity assays. J Immunol Methods 1983;65:55-63.

10. Kasugai S, Hasegawa N, Ogura H. A simple in vitro cytotoxicity test using the MTT (3-(4,5)-dimethylthiazol-2-yl)-2,5-diphenyl tetrazolium bromide) colorimetric assay: Analysis of eugenol toxicity on dental pulp cells (RPC-C2A). Jpn J Pharmacol 1990;52:95-100.

11. Boyden $S$. The chemotactic effect of mixtures of antibody and antigen on polymorphonuclear leucocytes. J Exp Med 1962;115:453-66.

12. Wikesjö UM, Baker PJ, Christersson LA, Genco RJ, Lyall RM, Hic S, et al. A biochemical approach to periodontal regeneration: Tetracycline treatment conditions dentin surfaces. J Periodontal Res 1986;21:322-9.

13. Alleyn CD, O'Neal RB, Strong SL, Scheidt MJ, Van Dyke TE, McPherson JC, et al. The effect of chlorhexidine treatment of root surfaces on the attachment of human gingival fibroblasts in vitro. J Periodontol 1991;62:434-8.

14. Melcher AH. On the repair potential of periodontal tissues. J Periodontol 1976;47:256-60.

15. Marx RE, Armentano L, Olavarria A, Samaniego J. RhBMP-2/ACS grafts versus autogenous cancellous marrow grafts in large vertical defects of the maxilla: An unsponsored randomized open-label clinical trial. Int J Oral Maxillofac Implants 2013;28:e243-51.

16. Matsuda N, Lin WL, Kumar NM, Cho MI, Genco RJ. Mitogenic, chemotactic, and synthetic responses of rat periodontal ligament fibroblastic cells to polypeptide growth factors in vitro. J Periodontol 1992;63:515-25.

17. Nishimura F, Terranova VP. Comparative study of the chemotactic responses of periodontal ligament cells and gingival fibroblasts to polypeptide growth factors. J Dent Res 1996;75:986-92.

18. Celotti F, Colciago A, Negri-Cesi P, Pravettoni A, Zaninetti R, Sacchi MC, et al. Effect of platelet-rich plasma on migration and proliferation of saOS-2 osteoblasts: Role of platelet-derived growth factor and transforming growth factor-beta. Wound Repair Regen 2006;14:195-202.
19. Gamal AY, Mailhot JM, Garnick JJ, Newhouse R, Sharawy MM Human periodontal ligament fibroblast response to PDGF-BB and IGF-1 application on tetracycline HCI conditioned root surfaces. J Clin Periodontol 1998;25:404-12.

20. Creeper F, Lichanska AM, Marshall RI, Seymour GJ, Ivanovski S. The effect of platelet-rich plasma on osteoblast and periodontal ligament cell migration, proliferation and differentiation. J Periodontal Res 2009;44:258-65.

21. Graziani F, Ivanovski S, Cei S, Ducci F, Tonetti M, Gabriele M, et al. The in vitro effect of different PRP concentrations on osteoblasts and fibroblasts. Clin Oral Implants Res 2006;17:212-9.

22. Choi BH, Zhu SJ, Kim BY, Huh JY, Lee SH, Jung JH, et al. Effect of platelet-rich plasma (PRP) concentration on the viability and proliferation of alveolar bone cells: An in vitro study. Int J Oral Maxillofac Surg 2005;34:420-4.

23. Dennison DK, Vallone DR, Pinero GJ, Rittman B, Caffesse RG. Differential effect of TGF-beta 1 and PDGF on proliferation of periodontal ligament cells and gingival fibroblasts. J Periodontol 1994;65:641-8.

24. Mumford JH, Carnes DL, Cochran DL, Oates TW. The effects of platelet-derived growth factor-BB on periodontal cells in an in vitro wound model. J Periodontol 2001;72:331-40.

25. Okuda K, Kawase T, Momose M, Murata M, Saito Y, Suzuki H, et al. Platelet-rich plasma contains high levels of platelet-derived growth factor and transforming growth factor-beta and modulates the proliferation of periodontally related cells in vitro. J Periodontol 2003;74:849-57.

26. Fréchette JP, Martineau I, Gagnon G. Platelet-rich plasmas: Growth factor content and roles in wound healing. J Dent Res 2005;84:434-9.

27. Seifert RA, Hart CE, Phillips PE, Forstrom JW, Ross R, Murray MJ, et al. Two different subunits associate to create isoform-specific platelet-derived growth factor receptors. J Biol Chem 1989;264:8771-8.

28. Arnoczky SP, Delos D, Rodeo SA. What is plateletrich plasma? Oper Tech Sports Med 2011;19:1428.

29. Appel TR, Pötzsch B, Müller J, von Lindern JJ, Bergé SJ, Reich RH, et al. Comparison of three different preparations of platelet concentrates for growth factor enrichment. Clin Oral Implants Res 2002;13:522-8.

30. Nagata MJ, Messora MR, Furlaneto FA, Fucini SE, Bosco AF, Garcia VG, et al. Effectiveness of two methods for preparation of autologous platelet-rich plasma: An experimental study in rabbits. Eur J Dent 2010;4:395-402.

31. Landesberg R, Moses M, Karpatkin M. Risks of using platelet rich plasma gel. J Oral Maxillofac Surg 1998;56:1116-7. 